\title{
THE UROFLOWMETER
}

\author{
By G. H. Foster, M.A., B.M., F.R.C.S. and \\ JoHN M. O'BrIEN, M.A., M.B., F.R.C.S. \\ Urological Unit, Western General Hospital, Edinburgh
}

THE rate of flow of urine is related to the force of bladder contraction and to the resistance urine encounters at the bladder neck and in the urethra. In patients with outflow obstruction or bladder atony, the reduction of the flow rate is so obvious that it is a presenting symptom, the patient stating that he takes much longer to empty his bladder. With urethral obstruction there are other associated changes including reduction in the calibre of the urinary stream.

Observation of the act of micturition is therefore helpful in the diagnosis of disease of the lower urinary tract, but it is not always convenient and may embarrass both patient and doctor. The estimation of the degree of narrowing of the urinary stream is subject to the interpretation of the urologist. Indeed not only may the urologist differ from the patient, but individual urologists are likely to differ amongst themselves and the accurate estimation of progressive narrowing of the urinary stream, over a period of months or years, is very difficult. In an attempt to acquire definite objective evidence of urinary flow in graphic form, an apparatus was designed to measure urinary flow thereby complimenting subjective impressions. It was also hoped that the graph may give some indication as to the actual need for treatment and be of value in analysing the results of treatment.

Many methods for monitoring the course of micturition have previously been described in the literature (Drake, I948; von Garrelts, I956; Kaufman, 1957).

The measurement of the amount of urine passed per unit time is the parameter for estimating urinary flow, but the first attempts in this direction were only made just over 20 years ago. In 1948 Drake constructed a simple apparatus called the uroflowmeter. In this the urine was passed into a container suspended by a spring and the increasing weight of the urine was recorded as a function of time on a kymographic record. Kaufman in 1957 modified the uroflowmeter by incorporating an electrical starting mechanism.

More sophisticated methods have been constructed based on the principle of time volume correlation. von Garrelts (1956) included a device which simultaneously and automatically recorded the actual flow rate. Later Backman and von Garrelts (1963) modified this apparatus, the end product resembling very much the machine to be described in this article.

In 1966, in response to a request to evaluate a drug for the treatment of prostatic carcinoma, Dr. Cattrell of the Medical Physics Deparment of the University of Edinburgh was asked to devise an apparatus to measure urinary flow.

Apparatus Description. The apparatus is very simple. Urine is passed into a conical wide-mouthed container which is placed on a balance of the parallelogram type. The weight of the urine causes the container to descend and depress a central core within a fixed coil field. As a result, the greater the weight of urine, 
the greater the number of electrical impulses produced which are conveyed to an amplifier and in turn to a recorder. The apparatus is activated by a foot or hand switch, whichever happens to be the most convenient.

The instrument is adjustable so that zero weight in the container gives a zero deflection. It has been shown that the system is linear up to $500 \mathrm{gr}$.

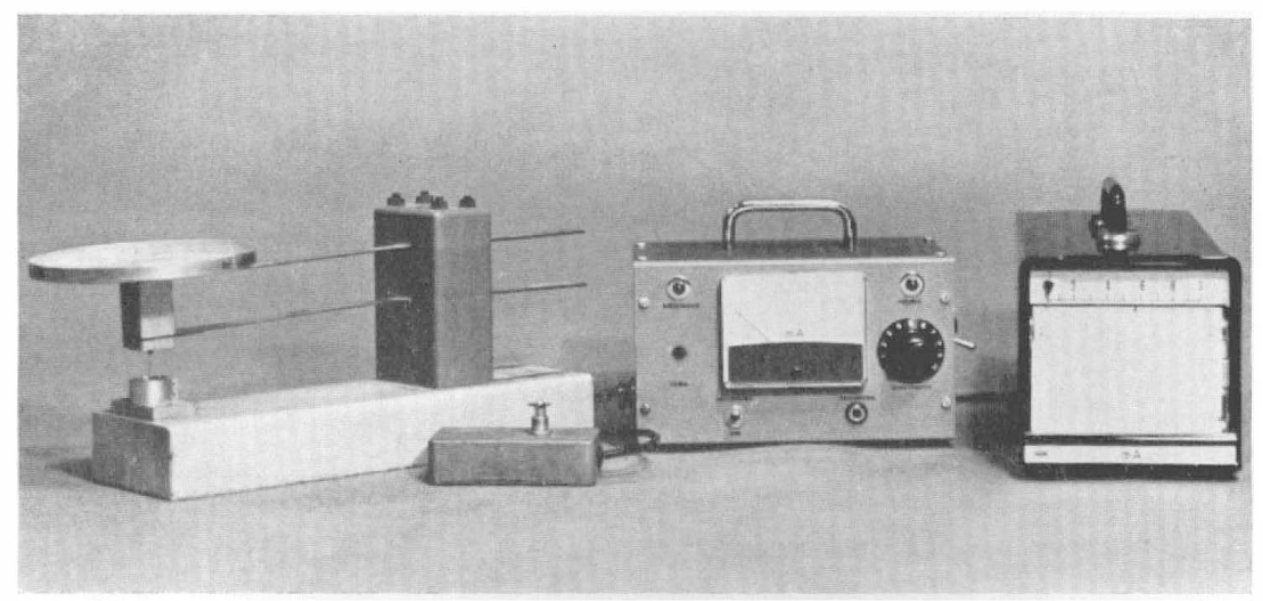

FIG. I

Uroflowmeter components (left to right): balance, switch, amplifier, recorder.

To establish normal values, several young healthy male patients were assessed and from these a value of $10 \mathrm{gm} / \mathrm{sec}$. or less was felt to be abnormal.

Method of taking the Record. The method of taking the record is simple and also has the advantage that the patient is alone, thereby avoiding possible embarrassment.

The patient is introduced to the machine and the principle of the experiment explained. Prior to initiating the procedure, it is essential that the patient's bladder is full because flow rates are related to the amount of urine passed. The individual is then asked to prepare himself for micturition with the foot poised over the foot switch. When the person feels absolutely ready for the act, and only then should he depress the foot switch and activate the motor. Immediately on finishing, and particularly when the bladder is felt to have completely emptied, the foot switch is depressed again to stop the motor.

A hand switch is a suitable alternative should there be any reason why the foot cannot be used.

Interpretation of the Graph. The difference between a normal record and that from a patient with gross obstruction is quite obvious. A normal person has a high flow rate, empties his bladder rapidly and terminates the act quickly.

The graph relates the weight of urine added with the passage of time and the voiding rate can be determined from the slope at any particular instant.

As the specific gravity of urine is fairly constant and approximates that of water, voiding rates are calculated in grams/sec. as the apparatus measures the weight of the urine and not its volume. 

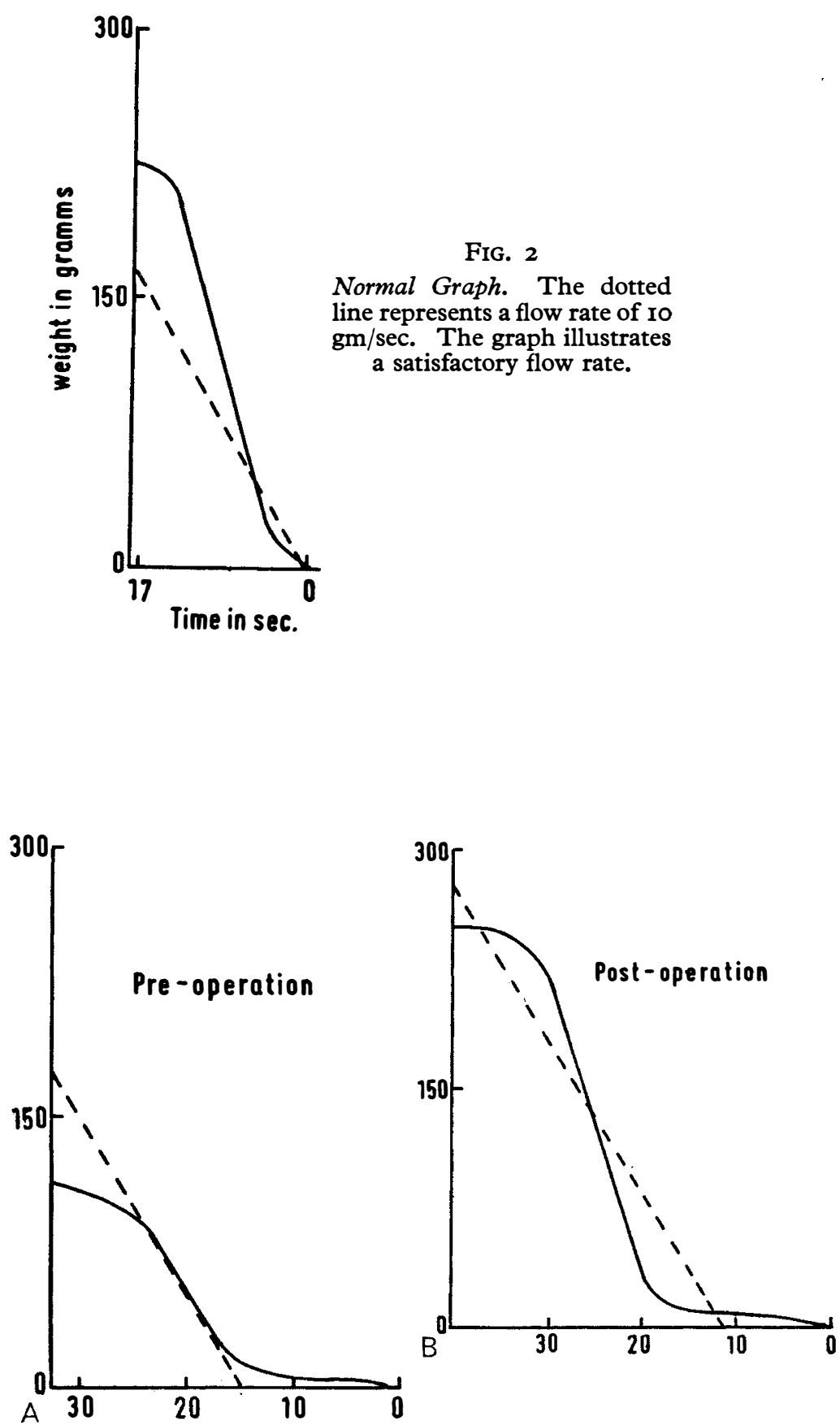

FIG. 3

Pre- and post-operative tracings from a patient with benign prostatic hypertrophy. Improved flow rate is seen following prostatectomy. 


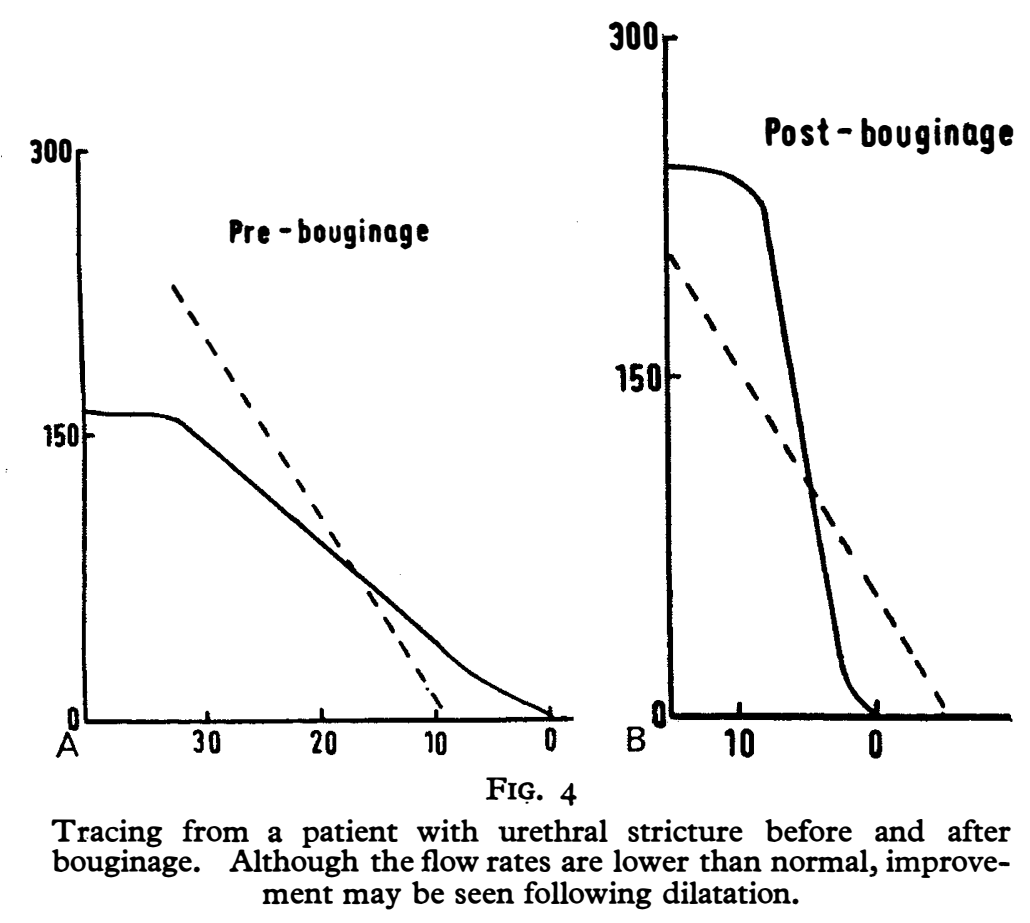

Clinical Usage. Initial studies have included patients with carcinoma of the prostate, simple prostatic hypertrophy and urethral stricture. Tracings have been obtained both pre- and post-operatively.

It is suggested that the procedure may be of value in the management of patients with neuropathic bladder in that flow rate may be used as a complementary procedure to cystoscopy, residual urine estimation and cystometrogram, and is far simpler. In reviewing these patients, if the flow rate remains unchanged, it would be reasonable to assume that bladder function and urethral resistance has not significantly changed.

\section{SUMMARY}

A simple machine for measuring urinary flow is described. This machine would appear to give reproducible results.

Preliminary studies show the value of such a simple piece of equipment, which is easy to use in measuring urinary flow in benign prostatic hypertrophy, carcinoma of the prostate and urethral stricture.

In reviewing paraplegic patients, if the flow rates remain unchanged, it is unlikely that bladder function and urethral resistance have significantly altered.

It is hoped that the uroflowmeter may be of value in indicating the need for and results of treatment.

\section{REFERENCES}

Backman, Karl-AXel \& von GarRelts, B. (1963). Acta Chir. Scand. 126, I67-I7I. DRAKE, W. M. Jr. (1948). F. Urol. 59, 650-658.

voN Garrelts, B. (1956). Acta Chir. Scand. 112, 326-340.

KaUfMaN, J. J. (1957). F. Urol. 78, 97-I03. 